\title{
Analysis of segregation distortion and its relationship to hybrid barriers in rice
}

\author{
Reflinur ${ }^{1,2}$, Backki Kim¹, Sun Mi Jang ${ }^{1}$, Sang-Ho Chu', Yogendra Bordiya', Md Babul Akter ${ }^{1}$, Joohyun Lee \\ Joong Hyoun $\mathrm{Chin}^{4}$ and Hee-Jong Koh ${ }^{1 *}$
}

\begin{abstract}
Background: Segregation distortion (SD) is a frequently observed occurrence in mapping populations generated from crosses involving divergent genotypes. In the present study, ten genetic linkage maps constructed from reciprocal $F_{2}$ and $\mathrm{BC}_{1} \mathrm{~F}_{1}$ mapping populations derived from the parents Dasanbyeo (indica) and llpumbyeo (japonica) were used to identify the distribution, effect, and magnitude of the genetic factors underlying the mechanisms of SD between the two subspecies.
\end{abstract}

Results: SD loci detected in the present study were affected by male function, female function, and zygotic selection. The most pronounced SD loci were mapped to chromosome 3 (transmitted through male gametes), chromosome 5 (transmitted through male gametes), and chromosome 6 (transmitted through female gametes). The level of SD in $\mathrm{BC}_{1} \mathrm{~F}_{1}$ populations which defined by chi-square value independence multiple tests was relatively low in comparison to $F_{2}$ populations. Dasanbyeo alleles were transmitted at a higher frequency in both $F_{2}$ and $B C_{1} F_{1}$ populations, suggesting that indica alleles are strongly favored in inter-subspecific crosses in rice. SD loci in the present study corresponded to previously reported loci for reproductive barriers. In addition, new SD loci were detected on chromosomes 2 and 12.

Conclusion: The identification of the distribution of SD and the effect of genetic factors causing SD in genetic mapping populations provides an opportunity to survey the whole genome for new SD loci and their relationships to reproductive barriers. This provides a basis for future research on the elucidation of the genetic mechanisms underlying SD in rice, and will be useful in molecular breeding programs.

Keywords: Segregation distortion; Linkage map; Reproductive barrier

\section{Background}

Segregation distortion (SD) is defined as a deviation of the observed genotypic frequency from expected Mendelian segregation ratios. Genetic elements that cause SD are increasingly being recognized as a powerful evolutionary force (Sandler and Novitski 1957), and it is thought that $\mathrm{SD}$ is due to a number of causes including genetic, physiological, and/or environmental factors (Liu et al. 2008; Matsushita et al. 2003; Wang et al. 2009; Xu et al. 1997).

Several molecular mechanisms of SD have been reported in plants (Fishman et al. 2008; Fishman et al. 2001; Fishman and Willis, 2005; Harushima et al. 2002; Koide et al. 2008a; Koide et al. 2008b; Koide et al. 2011).

\footnotetext{
* Correspondence: heejkoh@snu.ac.kr

'Department of Plant Science, Plant Genomics and Breeding Institute, and Research Institute for Agriculture and Life Sciences, Seoul National University, Seoul 151-921, Korea

Full list of author information is available at the end of the article
}

As reproductive isolation is a result of multiple genes acting at various stages throughout the life history of an organism, further dissection of SD regions in different populations and cross combinations is of key importance for breeding programs. In rice, previous studies detected loci linked with SD in both single and multiple crosses (Harushima et al. 2001, 2002; Wang et al. 2009). Use of abundant DNA markers allowed development of high-density linkage maps for rice, and these were used to survey the whole genome for SD loci (Causse et al. 1994; Harushima et al. 1996; Yano et al. 1998). Most of the barriers were mapped at different loci and demonstrated to have formed after japonica-indica differentiation (Harushima et al. 2001, 2002).

Since varietal differentiation in $O$. sativa is complex, data obtained from a single cross are not representative of the full range of differentiating Asian rice (Harushima et al. 2002). Thus, Harushima et al. (2002) used multiple 
crosses to investigate the diverse variation of reproductive barriers in rice. In that experiment, 33 reproductive barriers were identified, 15 of which affected the gametophyte and 18 of which altered viability of the zygote. However, as a probable consequence of the cross combinations used, the experiment was unable to clearly distinguish between female and male gametophytic selection-originated SDs. Therefore, the use of different mapping populations would be likely to reveal distorted loci or causes of SD that were not identified previously.

In the present study, two reciprocal $F_{2}$ and eight $\mathrm{BC}_{1} \mathrm{~F}_{1}$ populations developed from two Korean popular rice cultivars, Ilpumbyeo (japonica) and Dasanbyeo (indica), were used to investigate SD. Nuclear genetic or cytoplasmic factors influencing SD rates were inferred from the distortion patterns of DNA markers in reciprocal $\mathrm{F}_{2}$ populations. Gametophytic and zygotic selection as mechanisms underlying $\mathrm{SD}$ were inferred from distorted marker patterns in $\mathrm{BC}_{1} \mathrm{~F}_{1}$ populations conferring female- or male-segregating populations. Information regarding the loci and other factors responsible for SD in rice are important for the selection of breeding cultivars, and could also be beneficial for the development of molecular breeding programs. In this study, we aimed to map the genomic regions showing SD and to characterize whether gametic- or zygotic selection caused SD at each locus.

\section{Results}

\section{Construction of linkage maps in two $F_{2}$ and eight $B C_{1} F_{1}$ populations}

Total map length, average distance between adjacent markers, and the linkage map coverage of the genome constructed from reciprocal $\mathrm{F}_{2}$ and $\mathrm{BC}_{1} \mathrm{~F}_{1}$ populations was variable in the different mapping populations (Table 1). Physical locations of both end markers for each chromosome and linkage map coverage of the genome constructed from these populations in details were presented in Additional file 1: Table S1. The total map length in the Ilpumbyeo/Dasanbyeo (ID) population was 1391.1cM, with an average distance of $13.3 \mathrm{cM}$ between adjacent markers. In the reciprocal cross (DI), total map length and average distance were $1462.7 \mathrm{cM}$ and $13.9 \mathrm{cM}$, respectively. With a few exceptions, map lengths in female-segregating populations $\left(\mathrm{BC}_{1} \mathrm{~F}_{1}\right.$ populations in which $\mathrm{F}_{1}$ was used as a female parent) were generally longer than those in malesegregating population $\left(\mathrm{BC}_{1} \mathrm{~F}_{1}\right.$ populations in which $\mathrm{F}_{1}$ was used as a male parent) (Table 1 ). Reduction in map length was extreme when Ilpumbyeo as a maternal parent was crossed with $\mathrm{F}_{1}$ as a pollen parent. The map lengths of ID//I and DI//I were $1424.1 \mathrm{cM}$ and $1514.8 \mathrm{cM}$, respectively, while those of I//ID and I//DI were $525.8 \mathrm{cM}$ and 787.3cM, respectively (Table 1 ). This indicates that the frequency of recombination between marker pairs in I//ID and I//DI is lower than those in ID//I and DI//I.

\section{SD of DNA markers in two reciprocal $F_{2}$ populations}

On the whole, considering the single test performed at every marker locus, significant (acceptance level: 0.05) deviation with respect to expected Mendelian ratio in two $F_{2}$ populations was found at a high number of distorted markers on almost all chromosomes (Table 2).

Overall, $45(43.7 \%)$ and $41(40.2 \%)$ loci were significantly distorted from the expected Mendelian segregation ratios in the ID and DI populations, respectively

Table 1 Comparison of total map length and average distance between adjacent markers in genetic linkage map between reciprocal $F_{2}$ and $\mathrm{BC}_{1} \mathrm{~F}_{\mathbf{1}}$ populations generated from Dasanbyeo and Ilpumbyeo parents

\begin{tabular}{lllllll}
\hline Population & Generation & $\begin{array}{l}\text { Number of } \\
\text { tested loci }\end{array}$ & $\begin{array}{l}\text { Mapped } \\
\text { loci }\end{array}$ & $\begin{array}{l}\text { Total map } \\
\text { length (cM) }\end{array}$ & $\begin{array}{l}\text { Average distance } \\
\text { btw markers (cM) }\end{array}$ & $\begin{array}{c}\text { Map coverage(\%) } \\
\text { Genetic map }\end{array}$ \\
\hline I/D & $F_{2}$ & 107 & 103 & 1391.1 & 13.3 & 79.63 \\
Physical map
\end{tabular}

${ }^{a}$ map coverage in genetic and physical maps was based on the reference of Nipponbare/Kasalath map (Harushima et al. 1998) and IRGSP build5 (http://www.rgp.dna.affrc.go.jp/), respectively.

$\mathrm{ID}=\mathrm{F}_{2}$ of Ilpumbyeo $\mathrm{x}$ Dasanbyeo; $\mathrm{DI}=\mathrm{F}_{2}$ of Dasanbyeo $\mathrm{x}$ Ilpumbyeo

$\mathrm{ID} / / \mathrm{D}=$ = Ilpumbyeo/Dasanbyeo//Dasanbyeo, ID//I = Ipumbyeo/Dasanbyeo//Ilpumbyeo.

$\mathrm{DI} / / \mathrm{D}=$ Dasanbyeo/Ilpumbyeo//Dasanbyeo,DI//I = Dasanbyeo/Ilpumbyeo//Ipumbyeo.

$\mathrm{I} / / \mathrm{ID}$ = Ilpumbyeo//Ipumbyeo/Dasanbyeo; I//DI = Ilpumbyeo//Dasanbyeo//Ipumbyeo.

$\mathrm{D} / / \mathrm{ID}=$ Dasanbyeo//Ilpumbyeo/Dasanbyeo; and D//DI = Dasanbyeo//Dasanbyeo/Ilpumbyeo. 
Table 2 Number of regions of segregation distortion loci detected in two reciprocal $F_{2}$ and eight $B C_{1} F_{1}$ populations generated from Ilpumbyeo and

\section{Dasanbyeo}

\begin{tabular}{|c|c|c|c|c|c|c|c|c|c|c|c|}
\hline \multirow[t]{3}{*}{ Pop. $^{\text {a }}$} & \multirow{3}{*}{$\begin{array}{l}\text { Mapped } \\
\text { loci }\end{array}$} & \multirow{2}{*}{\multicolumn{2}{|c|}{ Loci of SD }} & \multirow{3}{*}{$\begin{array}{l}\text { Number of } \\
\text { regions of } S D^{d}\end{array}$} & \multirow[t]{3}{*}{ Chromosomal regions of SD } & \multicolumn{6}{|c|}{ Favored genotype (ratio, \%) } \\
\hline & & & & & & \multicolumn{2}{|c|}{ Ilpumbyeo (II) } & \multicolumn{2}{|c|}{ Heterozygote (ID or DI) } & \multicolumn{2}{|c|}{ Dasanbyeo (DD) } \\
\hline & & Single test $^{\mathrm{b}}$ & Multiple test $^{c}$ & & & Single test & Multiple test & Single test & Multiple test & Single test & Multiple test \\
\hline ID & 103 & $45(43.7 \%)$ & $27(26.2 \%)$ & 10 & $\begin{array}{l}\text { Chr.1 (1), Chr.3 (2),Chr.4 (1), Chr.5 (1), } \\
\text { Chr.6 (1), Chr.9 (1), Chr.12 (3) }\end{array}$ & - & - & $11(24.4 \%)$ & $4(14.8)$ & $34(75.6 \%)$ & $23(85.2 \%)$ \\
\hline DI & 102 & $41(40.2 \%)$ & $20(19.6 \%)$ & 8 & $\begin{array}{l}\text { Chr.1 (1), Chr.3 (1), Chr.4 (1), Chr.5 (1), } \\
\text { Chr.6 (1), Chr.12 (3) }\end{array}$ & $1(2.5 \%)$ & - & $14(34.1 \%)$ & $4(20 \%)$ & $26(63.4 \%)$ & $16(80 \%)$ \\
\hline ID//D & 140 & $7(5.0 \%)$ & 0 & 0 & & - & - & $3(42.9 \%)$ & - & $4(57.1 \%)$ & - \\
\hline $\mid \mathrm{D} / / \mathrm{I}$ & 142 & $28(19.7 \%)$ & $7(4.9 \%)$ & 1 & Chr.6 (1) & $18(64.3 \%)$ & $5(71.4 \%)$ & $10(35.7 \%)$ & $2(28.6 \%)$ & - & - \\
\hline DI/D & 139 & $23(15.8 \%)$ & $5(3.6 \%)$ & 3 & Chr.1 (1), Chr.6 (1), Chr.12 (1) & - & - & $10(43.5 \%$ & $1(20 \%)$ & $13(56.5 \%)$ & $4(80 \%)$ \\
\hline $\mathrm{DI} / / \mathrm{I}$ & 140 & $11(7.9 \%)$ & $7(5 \%)$ & 1 & Chr.6 (1) & $5(45.5 \%)$ & - & $6(54.5 \%)$ & $7(100 \%)$ & - & - \\
\hline I//ID & 132 & $21(15.9 \%)$ & $11(8.3 \%)$ & 4 & Chr.1 (1), Chr.5 (1), Chr.8 (1), Chr.11 (1) & $21(100 \%)$ & $11(100 \%)$ & - & - & - & - \\
\hline |//DI & 135 & $25(18.5 \%)$ & $2(2.2 \%)$ & 1 & Chr.12 (1) & $1(4.0 \%)$ & $2(100 \%)$ & $24(96.0 \%)$ & - & - & - \\
\hline $\mathrm{D} / / \mathrm{ID}$ & 139 & 39 (28.1\%) & $11(7.9 \%)$ & 5 & $\begin{array}{l}\text { Chr.1 (1), Chr.3 (1), Chr.5 (1), Chr.8 (1), } \\
\text { Chr.12 (1) }\end{array}$ & - & - & $2(5.1 \%)$ & - & $37(94.9 \%)$ & $11(100 \%)$ \\
\hline $\mathrm{D} / / \mathrm{DI}$ & 142 & $44(31.0 \%)$ & $18(12.7 \%)$ & 6 & $\begin{array}{l}\text { Chr.2 (1), Chr.3 (1), Chr.5 (2), Chr.8 (1), } \\
\text { Chr.12 (1) }\end{array}$ & - & - & $5(11.4 \%)$ & - & $39(88.6 \%)$ & $12(100 \%)$ \\
\hline
\end{tabular}

arefer to Table 1 for abbreviations.

bObserved segregation to Mendelian expectation was tested using a Chisquare value by single testing (randomly selected single marker).

'Observed segregation to Mendelian expectation was tested using a Chisquare value by multiple testing (sequential Bonferroni correction of $P$-value) across loci separately within each cross.

${ }^{\mathrm{d}} \mathrm{SD}$ is abbreviation of segregation distortion. 
(Table 2). With this acceptance level (alpha 0.05), it can be suggested that $5 \%$ of the non-Mendelian segregation were caused by chance. However, to detect false $\mathrm{H}_{0}$ upon applying the sequential Bonferroni method, the number of possible SD was extremely reduced. After applying Bonferroni method to segregation data, significant results in 27 out of 45 SD loci in ID population were obtained, which means that $26.2 \%$ of the total number of segregation analyzed were non-Mendelian. On the other hand, we obtained significant results in 20 out 41 SD loci in DI population, which means that the SD level decreased from $40.2 \%$ to $19.6 \%$ (Table 2). Most of the distorted markers in both $\mathrm{F}_{2}$ populations were skewed towards Dasanbyeo alleles, indicating that indica alleles were transmitted at higher frequency than japonica alleles.

\section{Nuclear and cytoplasmic effects on SD in reciprocal $F_{2}$ populations}

It can be inferred that nuclear genetic factors are responsible for SD if markers are similarly distorted in both reciprocal $\mathrm{F}_{2}$ populations. Conversely, a cytoplasmic effect can be inferred if the markers are distorted in only one of the reciprocal $\mathrm{F}_{2}$ populations. A total of 18 markers were distorted in both $F_{2}$ populations (Additional file 2: Table S2), and were thus caused by nuclear genetic factors. Eleven markers deviated from the expected Mendelian segregation ratio in only one of the two reciprocal $\mathrm{F}_{2}$ populations (Additional file 2: Table S2), indicating a cytoplasmic effect. Of these 11 markers, 9 showed SD only in the ID population and 2 showed SD only in the DI population. Favored marker genotypes differed between the ID (Ilpumbyeo cytoplasm) and DI populations (Dasanbyeo cytoplasm); specifically, seven of the $9 \mathrm{SD}$ markers (Additional file 2: Table S2) in the ID population favored Dasanbyeo genotypes and the remaining two loci favored heterozygous genotypes, while two SD loci in the DI population favored Dasanbyeo genotypes (Additional file 2: Table S2 and Additional file 3: Figure S1).

\section{Effect of gametophytic and zygotic factors on SD in reciprocal $\mathrm{BC}_{1} \mathrm{~F}_{1}$ populations}

Number of regions of $\mathrm{SD}$ and the chromosomal regions associated with $\mathrm{SD}$ from eight $\mathrm{BC}_{1} \mathrm{~F}_{1}$ populations are presented in Table 2 and Table 3, respectively. To determine whether the SD loci detected in the $\mathrm{F}_{2}$ populations originated from female function (embryo-sac effect), male function (pollen effect), or post-fertilization selection among zygotes (hereafter, zygotic selection), genotype ratios were compared in pairs of reciprocal backcross to each parent. The significant SD detected in the $\mathrm{BC}_{1} \mathrm{~F}_{1}$ populations only when the $\mathrm{F}_{1}$ was used as a female parent is indicative of SD due to the female effect since there was no segregation in male parent. By contrast, $\mathrm{SD}$ detected in the $\mathrm{BC}_{1} \mathrm{~F}_{1}$ population only when the $F_{1}$ male was used as a parent is indicative of the male effect since there was no segregation in the female parent. However, when markers showed SD in both backcrosses, SD is indicative of zygotic selection. Our data thus suggest three mechanisms that lead to SD, as follows: SD through female function, SD through male function, and SD through zygotic selection.

\section{SD through female function}

On the basis of SD patterns observed in $\mathrm{BC}_{1} \mathrm{~F}_{1}$ conferring female-segregating populations $\left(\mathrm{F}_{1}\right.$ plants were used as female parents), two chromosomal regions (chromosomes 6 and 12) harbored SD loci putatively influenced by female function, hereafter termed female-specific SD loci or fSD (Table 3). Of these, female-function influence on SD was most pronounced in chromosome 6, as indicated by segregation distortion of the marker loci in three of the female-segregating populations (ID//I, DI// $\mathrm{D}, \mathrm{DI} / \mathrm{I})$, but not in the reciprocal backcrosses (I//ID, $\mathrm{D} / / \mathrm{DI}, \mathrm{I} / / \mathrm{DI})$. Thus, a region encompassing the markers S06018 and S06031 on chromosome 6 was subject to significant transmission bias in all female-segregating populations with the exception of ID//D (Table 3). Moreover, in the ID//I and DI//I populations, the marker distortion affect extended to the neighboring region (S06040B, S06053, and S06065), resulting in the presence of severely distorted markers across a large portion of chromosome 6 (Additional file 4: Figure S2). In contrast, inheritance of these markers was undistorted in the male-segregating population, implying that the SD was caused by femalespecific function only and that pollen grain competition is not responsible for SD detected on chromosome 6. Our finding is in accordance with the earlier studies about SD in japonica-indica hybrids conducted by Lin et al. (1992). In their study, when pollen from $\mathrm{F}_{1}$ hybrids were used for backcrossing, no segregation distortion was found for marker gene loci on chromosome 6 and thus, they suggested that SD of markers on chromosome 6 is caused through partial female gamete abortion in indica-japonica hybrids. In addition, SD through female function on chromosome 6 could also be caused and explained by reducing of spikelet fertility since the certain SD regions was concurred with qSF6.1 (S06031-S06040B) and qSF6.2 (S06040B-S06053) loci responsible for hybrid fertility genes in our previous study (Reflinur et al. 2012).

Dasanbyeo alleles were over-represented at all distorted markers on chromosome 6 in the three populations, as determined by the skew direction. This indicates that Dasanbyeo embryo sacs were preferred during fertilization by both Dasanbyeo and Ilpumbyeo pollen, thus causing the distortion of certain regions on chromosome 6 . The same chromosome 6 markers segregated normally in the 
Table 3 Characterization of segregation distortion loci underlying the transmission of gametes through female, male and zygotic selections

\begin{tabular}{|c|c|c|c|c|c|c|c|c|c|c|c|c|c|}
\hline $\mathrm{Chr}^{\mathrm{a}}$ & Marker & $\begin{array}{l}\text { Position } \\
\text { (Mbp) }\end{array}$ & $\begin{array}{l}\% \mathrm{DD}^{\mathbf{b}} \\
\text { (ID) }\end{array}$ & $\begin{array}{l}\% \mathrm{DD} \\
\text { (DI) }\end{array}$ & $\begin{array}{l}\% \mathrm{DD} \\
\text { (ID//D) }\end{array}$ & $\begin{array}{l}\text { \%DD } \\
\text { (D//ID) }\end{array}$ & $\begin{array}{l}\text { \%DD } \\
\text { (DI//D) }\end{array}$ & $\begin{array}{l}\text { \%DD } \\
\text { (D//DI) }\end{array}$ & $\begin{array}{l}\% \text { II } \\
\text { (ID//I) }\end{array}$ & $\begin{array}{l}\text { \%ll } \\
\text { (I//ID) }\end{array}$ & $\begin{array}{l}\% \text { Il } \\
\text { (DI//I) }\end{array}$ & $\begin{array}{l}\% \text { II } \\
\text { (I//DI) }\end{array}$ & Mechanism $^{c}$ \\
\hline 1 & S01022 & 4.38 & $0.36^{* *(D D)}$ & $0.34^{* *(D D)}$ & & $0.78^{* *(\mathrm{DD})}$ & $0.71^{* *(\mathrm{DD})}$ & & & & & & Zygotic selection \\
\hline 1 & S01038 & 7.46 & $0.34^{* *(\mathrm{DD})}$ & $0.36^{* *(\mathrm{DD})}$ & & $0.75^{* *(\mathrm{DD})}$ & $0.73^{* *(\mathrm{DD})}$ & & & & & & Zygotic selection \\
\hline 1 & S01157B & 39.8 & & & & & & & & $0.83^{* *(I I)}$ & & & $\mathrm{mSD}$ \\
\hline 1 & S01160 & 40.80 & & & & & & & & $0.84^{* *(I I)}$ & & & $\mathrm{mSD}$ \\
\hline 1 & S01181B & 43.20 & & & & & & & & $0.84^{* *(I I)}$ & & & $\mathrm{mSD}$ \\
\hline 2 & S02126 & 29.91 & & & & & & $0.68^{* *(D D)}$ & & & & & $\mathrm{mSD}$ \\
\hline 2 & S02135 & 31.48 & & & & & & $0.69^{* *(D D)}$ & & & & & $\mathrm{mSD}$ \\
\hline 3 & S03027 & 5.71 & $0.38^{* *(\mathrm{DD})}$ & $0.34^{* *(\mathrm{DD})}$ & & & & $0.77^{* *(D D)}$ & & & & & $\mathrm{mSD}$ \\
\hline 3 & S03041 & 8.90 & $0.38^{* *(D D)}$ & $0.41^{* *(\mathrm{DD})}$ & & $0.79^{* *(D D)}$ & & $0.87^{* *(D D)}$ & & & & & $\mathrm{mSD}$ \\
\hline 3 & S03046 & 10.14 & $0.41^{* *(D D)}$ & $0.41^{* *(D D)}$ & & $0.79^{* *(D D)}$ & & $0.91^{* *(D D)}$ & & & & & $\mathrm{mSD}$ \\
\hline 3 & S03048 & 10.75 & $0.41^{* *(\mathrm{DD})}$ & $0.40^{* *(\mathrm{DD})}$ & & $0.83^{* *(\mathrm{DD})}$ & & $0.89^{* *(\mathrm{DD})}$ & & & & & $\mathrm{mSD}$ \\
\hline 3 & S03065 & 14.43 & - & - & & $0.83^{* *(\mathrm{DD})}$ & & $0.94^{* *(D D)}$ & & & & & $\mathrm{mSD}$ \\
\hline 3 & S03130 & 29.83 & $0.32^{* *(\mathrm{DD})}$ & & & & & & & & & & Cytoplasm effect \\
\hline 3 & S03136 & 30.11 & $0.33^{* *(D D)}$ & & & & & & & & & & Cytoplasm effect \\
\hline 4 & S04113 & 32.61 & $0.22^{* *(H)}$ & $0.21^{* *(\mathrm{H})}$ & & & & & & & & & Nuclear effect \\
\hline 4 & S04120 & 33.60 & $0.14^{* *(H)}$ & $0.16^{* *(\mathrm{H})}$ & & & & & & & & & Nuclear effect \\
\hline 5 & S05004B & 0.29 & $0.41^{* *(\mathrm{DD})}$ & $0.33^{* *(\mathrm{H})}$ & & $0.73^{* *(\mathrm{DD})}$ & & $0.78^{* *(D D)}$ & & & & & $\mathrm{mSD}$ \\
\hline 5 & S05009 & 0.84 & $0.39^{* *(D D)}$ & $0.26^{* *(\mathrm{H})}$ & & $0.73^{* *(\mathrm{DD})}$ & & $0.83^{* *(D D)}$ & & & & & $\mathrm{mSD}$ \\
\hline 5 & S05029 & 3.42 & $0.34^{* *(\mathrm{DD})}$ & $0.35^{* *(\mathrm{DD})}$ & & $0.75^{* *(\mathrm{DD})}$ & & $0.81^{* *(\mathrm{DD})}$ & & & & & $\mathrm{mSD}$ \\
\hline 5 & S05030A & 3.66 & $0.33^{* *(D D)}$ & $0.33^{* *(D D)}$ & & $0.77^{* *(D D)}$ & & $0.80^{* *(D D)}$ & & & & & $\mathrm{mSD}$ \\
\hline 5 & S05030B & 3.66 & $0.33^{* *(\mathrm{DD})}$ & $0.33^{* *(\mathrm{DD})}$ & & $0.77^{* *(\mathrm{DD})}$ & & $0.77^{* *(D D)}$ & & & & & $\mathrm{mSD}$ \\
\hline 5 & S05032 & 4.29 & & $0.34^{* *(\mathrm{DD})}$ & & & & $0.74^{* *(\mathrm{DD})}$ & & $0.84^{* *(H)}$ & & & $\begin{array}{l}\text { mSD + Cytoplasm } \\
\text { effect }\end{array}$ \\
\hline 5 & S05036 & 4.71 & & $0.35^{* *(\mathrm{DD})}$ & & & & $0.74^{* *(\mathrm{DD})}$ & & $0.80^{* *(\mathrm{H})}$ & & & $\begin{array}{l}\text { mSD + Cytoplasm } \\
\text { effect }\end{array}$ \\
\hline 5 & S05045 & 6.97 & - & - & & & & $0.73^{* *(D D)}$ & & $0.80^{* *(H)}$ & & & $\mathrm{mSD}$ \\
\hline 5 & S05064 & 16.99 & & & & & & $0.73^{* *(\mathrm{DD})}$ & & $0.84^{* *(H)}$ & & & $\mathrm{mSD}$ \\
\hline 5 & S05077A & 20.10 & & & & & & $0.72^{* *(D D)}$ & & $0.80^{* *(H)}$ & & & $\mathrm{mSD}$ \\
\hline 6 & S06018 & 4.74 & $0.36^{* *(D D)}$ & $0.37^{* *(D D)}$ & & & $0.68^{* *(\mathrm{DD})}$ & & $0.34^{* *(\mathrm{H})}$ & & $0.26^{* *(\mathrm{H})}$ & & fSD \\
\hline 6 & S06031 & 5.68 & $0.36^{* *(D D)}$ & $0.36^{* *(D D)}$ & & & $0.67^{* *(D D)}$ & & $0.30^{* *(\mathrm{H})}$ & & $0.25^{* *(\mathrm{H})}$ & & fSD \\
\hline 6 & S06040 & 7.83 & & & & & & & $0.26^{* *(\mathrm{H})}$ & & $0.19^{* *(\mathrm{H})}$ & & $\mathrm{fSD}$ \\
\hline 6 & S06053 & 8.83 & & & & & & & $0.22^{* *(\mathrm{H})}$ & & $0.22^{* *(\mathrm{H})}$ & & fSD \\
\hline 6 & S06065A & 14.53 & & & & & & & $0.29^{* *(H)}$ & & $0.23^{* *(H)}$ & & fSD \\
\hline 8 & S08060 & 17.27 & & & & $0.25^{* *(\mathrm{H})}$ & & $0.33^{* *(\mathrm{H})}$ & & $0.84^{* *(I I)}$ & & & $\mathrm{mSD}$ \\
\hline 8 & S08066 & 18.91 & & & & $0.23^{* *(\mathrm{H})}$ & & $0.31^{* *(\mathrm{H})}$ & & $0.80^{* *(I I)}$ & & & $\mathrm{mSD}$ \\
\hline 8 & S080075 & 20.65 & & & & $0.23^{* *(H)}$ & & $0.30^{* *(H)}$ & & $0.88^{* *(I I)}$ & & & $\mathrm{mSD}$ \\
\hline 8 & S08080B & 21.33 & & & & $0.23^{* *(\mathrm{H})}$ & & $0.27^{* *(\mathrm{H})}$ & & $0.84^{* *(I I)}$ & & & $\mathrm{mSD}$ \\
\hline 8 & S08090 & 23.08 & & & & $0.19^{* *(\mathrm{H})}$ & & $0.28^{* *(\mathrm{H})}$ & & $0.84^{* *(I I)}$ & & & $\mathrm{mSD}$ \\
\hline 9 & S09065 & 17.91 & $0.19^{* *(H)}$ & & & & & & & & & & Cytoplasm effect \\
\hline 9 & S09075A & 19.58 & $0.20^{* *(\mathrm{H})}$ & & & & & & & & & & Cytoplasm effect \\
\hline 11 & S11004A & 1.08 & & & & & & & & $0.88^{* *(I I)}$ & & & $\mathrm{mSD}$ \\
\hline 11 & S11006 & 1.27 & & & & & & & & $0.88^{* *(I I)}$ & & & $\mathrm{mSD}$ \\
\hline 12 & S12005 & 0.33 & $0.90^{* *(\mathrm{DD})}$ & $0.89^{* *(\mathrm{DD})}$ & & & & & & & & & Nuclear effect \\
\hline
\end{tabular}




\begin{tabular}{|c|c|c|c|c|c|c|c|c|}
\hline 12 & S12009A & 0.63 & $0.39^{* *(D D)}$ & $0.43^{* *(\mathrm{DD})}$ & $0.78^{* *(\mathrm{DD})}$ & $0.71^{* *(\mathrm{DD})}$ & $0.18^{* *(H)}$ & $\mathrm{mSD}$ \\
\hline 12 & S12011B & 1.88 & $0.40^{* *(\mathrm{DD})}$ & $0.38^{* *(\mathrm{DD})}$ & $0.75^{* *(\mathrm{DD})}$ & $0.69^{* *(\mathrm{DD})}$ & $0.16^{* *(H)}$ & $\mathrm{mSD}$ \\
\hline 12 & S12030 & 3.84 & $0.36^{* *(\mathrm{DD})}$ & & & & & Cytoplasm effect \\
\hline 12 & S12039B & 5.57 & $0.31^{* *(\mathrm{DD})}$ & & & & & Cytoplasm effect \\
\hline 12 & S12055B & 15.57 & $0.35^{* *(\mathrm{DD})}$ & & & & & Cytoplasm effect \\
\hline 12 & S12066 & 19.44 & $0.33^{* *(\mathrm{DD})}$ & & \multicolumn{2}{|c|}{$0.23^{* *(H)}$} & & $\begin{array}{l}\text { fSD + Cytoplasm } \\
\text { effect }\end{array}$ \\
\hline 12 & S12071 & 19.66 & - & - & \multicolumn{2}{|c|}{$0.24^{* *(H)}$} & & fSD \\
\hline 12 & S12091 & 23.65 & - & - & \multicolumn{2}{|c|}{$0.24^{* *(\mathrm{H})}$} & & $\mathrm{fSD}$ \\
\hline 12 & S12097B & 25.00 & $0.41^{* *(\mathrm{DD})}$ & & \multicolumn{2}{|c|}{$0.25^{* *(\mathrm{H})}$} & & $\begin{array}{l}\text { fSD + Cytoplasm } \\
\text { effect }\end{array}$ \\
\hline
\end{tabular}

indicates chromosomal regions showing segregation distortion (SD) at least in one population.

${ }^{b}$ genotypic ratios were tested against the expected Mendelian expectation to determine significant of SD ( $x^{2}$ with 2 df for $F_{2}$, 1 df for backcrosses: **indicating locus showed significant deviation from Mendelian segregation ratio (Bonferroni corrected). DD and II are abbreviation for genotype frequency (\%) of Dasanbyeo and Ilpumbyeo, respectively. The direction of skewness is followed in bracket where DD for Dasanbyeo, II for Ilpumbyeo homozygous, and H for heterozygous genotypes. (-) indicating the primers were not tested in certain populations.

' factor causing segregation distortion, such as male function (mSD), female function (fSD), or zygotic selection. Male function (mSD) is defined if segregation ratios of those markers are significantly distorted from the expected mendelian segregation ratios in $\mathrm{BC}_{1} \mathrm{~F}_{1}$ types conferring male-segregating population, but in its reciprocal cross was normally segregated according to mendelian pattern. Whereas, female function (fSD) causing SD is defined by the markers that only distorted in the type of $\mathrm{BC}_{1} \mathrm{~F}_{1}$ conferring female-segregating population and normally segregated in its reciprocal cross. On the other hand, zygotic selection causing SD is explained by those markers which are distorted in $\mathrm{BC}_{1} \mathrm{~F}_{1}$ types conferring both female-and male segregating populations.

ID//D population, suggesting that this might be the best cross combination with which to obtain new recombinants among breeding $\mathrm{BC}_{1} \mathrm{~F}_{1}$ populations. The utility of this combination is further supported by the low observed frequency of SD, in which only seven (5\%) of the 140 sequence-tagged site STS markers ( $0 \%$ after correctedBonferroni) were distorted (Table 2). Although further study is required to determine the factors influencing low SD frequency in ID//D, this backcross direction can nevertheless be used to eliminate hybrid barriers causing $\mathrm{SD}$ in indica-japonica crosses.

Unlike evidence of SD on chromosome 6 which could be explained by female function on SD through 3 out 4 female-backcrossing populations, fSD on chromosome 12 (S12066, S12071, S12091, and S12097B) was found inconsistent. This region was distorted only in DI//D population while certain region was normally segregated in a Mendelian fashion in other three female-segregating populations (ID//D, ID//I, and DI//I). This inconsistency might be explained by preferential fertilization in which male gametophyte with $\mathrm{D}$ genotype interacts with maternal D genotype. The direction of skewness in this population was towards heterozygous (DI) genotypes indicating preferential segregation of Ilpumbyo allele during $F_{1}$ female meiosis giving rise to high probability of fertilization between Ilpumbyeo-embryosac and Dasanbyeo-pollen which caused transmission ratio distortion.

\section{SD through male function}

Seven SD loci putatively influenced by male function, hereafter denoted as male-specific SD loci or $\mathrm{mSD}$, were detected on distorted regions of chromosomes 1, 2, 3, 5, 8,11 and 12 . The regions harboring the most severe distortion patterns were on chromosomes 3,5 and 8 (Table 3). Markers showing SD on chromosome 3 were distorted in two of the four male-segregating backcross populations, D//ID and D//DI. The skew direction in both D//ID and D//DI was towards Dasanbyeo alleles. Both skew directions imply that Dasanbyeo pollens were preferred to Ilpumbyeo pollens when under competition. Similarly, SD observed on chromosome 5 at the loci S05004B, S05009, S05029, S05030A, and S05030B, were significant in D//ID and D//DI maps but not in their reciprocal backcross populations ID//D and DI//D. The fact that $\mathrm{mSD}$ on chromosome 3 and 5 was not observed in either I//ID or I//DI populations reflecting that preferential fertilization might be possible explanation for $\mathrm{mSD}$ on certain chromosome. In this case, male gametophytes with D genotype interacted with maternal D genotype loci and preferentially fertilized. Theory suggests that the meiotic drive elements such as gametophytic competition results in preferential fertilization or abortion of gamete or zygote, are the main influence factors of SD in plants (Lyttle, 1991; Taylor and Ingvarsson 2003), thus the mechanism showing by certain loci is most likely as a consequence of pollen competition (Table 3). However, the pollen fertility of $\mathrm{BC}_{1} \mathrm{~F}_{1}$ progeny was not observed in present study because poor number of backcross population size as a result of reduced fertility in $F_{1}$ pollen and spikelet fertility (Figure 1). In addition, significantly reduced pollen fertility observed in the two reciprocal $F_{1}$ plants was not affected by crossing direction (Figure 1) 


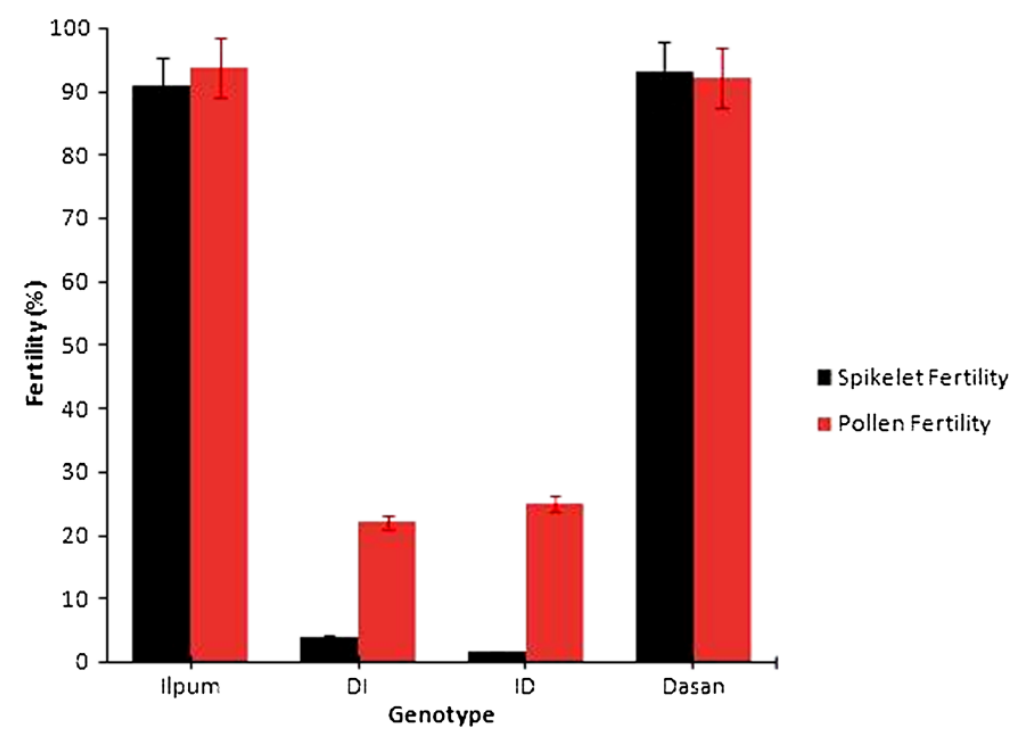

Figure 1 Pollen and spikelet fertility of parental lines and reciprocal $F_{1}$ plants derived from Ilpumbyeo and Dasanbyeo crosses. Both reciprocal $F_{1}$ plants showed low fertility of pollen and spikelet.

indicating that there might be no cytoplasmic effect on the expression of pollen fertility. However, it is likely that detected SD loci were explained by the fertilities. In particular D//DI population, the SD region extended further, spreading almost to the distal end of chromosome 5 as also observed in I//ID map (S05032, S05036, S05045, S05064, and S05077A) indicating the severity of the pollen competition effect (Additional file 4: Figure S2). However, the role of pollen competition effect on SD should be further clarified through in depth investigation of pollen fertility in $\mathrm{BC}_{1} \mathrm{~F}_{1}$ progeny. As in chromosome 3, distorted regions on chromosome 5 showed a preference for Dasanbyeo alleles. Dasanbyeo was over-represented in $\mathrm{D} / / \mathrm{ID}$ and $\mathrm{D} / / \mathrm{DI}$, whereas heterozygous was overrepresented in I//ID, indicating in both cases that Dasanbyeo pollens were preferred over Ilpumbyeo pollens when under competition.

Male-function influence on SD in chromosomes 8 and 12 was indicated by segregation distortion of the marker loci in three of the male-segregating populations (D//ID, $\mathrm{D} / / \mathrm{DI}, \mathrm{I} / / \mathrm{ID}$ ), but not in the reciprocal backcrosses (ID//I, DI//D, ID//I). Thus, a region encompassing the markers S08060 to S08090 on chromosome 8 and that of the markers S12009A and S12011 on chromosome 12 was subject to significant transmission bias in all male-segregating populations with the exception of I//ID (Table 3). However, unlike the case of $\mathrm{mSD}$ on chromosome 3,5 and 12 , Ilpumbyeo alleles were over-represented at all distorted markers on chromosome 8 in the three populations, as determined by the skew direction. Several inconsistencies of $\mathrm{mSD}$ loci were found on chromosome 1 and 11 which were only distorted in one out of four male-segregating populations. These regions were detected in I//ID population and the effect of distortion at these loci was skewed towards Ilpumbyeo alleles, implying that maternal I preferred male gametophyte with I genotype under pollen competition. Despite the fact that either $F_{1}$ plants developed from ID or DI crosses consist of Ilpumbyeo and Dasanbyeo pollen grains, when the two $F_{1}$ plants were used as male to fertilize the same female parents (Ilpumbyeo) to produce $\mathrm{BC}_{1} \mathrm{~F}_{1}$ plants, their effect on distortion was different that indicated by undistorted segregation of these regions in I//DI population. Thus, further study is needed to elucidate molecular mechanism of SD in these regions.

\section{SD through zygotic selection}

In addition to SD occurring as a consequence of female function and male function, zygotic selection was also observed to cause SD in our backcrossing populations. Zygotic selection causing biased transmission would be explained by the significant transmission ratio distortion in both reciprocal backcrosses. Regions exhibiting SD from zygotic selection only were located on the small part of chromosome 1 which indicated by the distortion of S01022 and S01038 markers in the D//ID and DI//D populations (Table 3). Zygotic selection in this region is due to either inviability of indica/japonica hybrid or related to spikelet fertility. Although earlier we were able to get around 100 lines for $\mathrm{BC}_{1} \mathrm{~F}_{1}$ whose $\mathrm{F}_{1}$ plants were used as female (embryosac source) and male (pollen sources) parents, the viable plants were very poor. Many $\mathrm{BC}_{1} \mathrm{~F}_{1}$ plants were died in seedlings stage reflecting hybrid weakness phenomenon in japonica/indica crosses and the number of lines survived in the field was decreased. Hence, we assumed that zygotic selection in this region is due to abortion of genotype ID or DI reflected 
by hybrid weakness reducing number of plants survived in the field both in D//ID (52 lines) and DI//D (69 lines). Another possible explanation that zygotic selection affected SD in this region is related to spikelet fertility. Mean value of spikelet fertility of lines showing heterozygous genotypes was lower than those lines carrying homozygous genotypes (data not shown).

\section{Discussion}

\section{SD across linkage maps}

Several gametophytic and zygotic barriers causing deviation of allele frequencies from Mendelian ratios have been reported in inter-specific rice crosses (Harushima et al. 1996; Harushima et al. 2002; Koide et al. 2008b; Wang et al. 2005, 2009). In the present study, a similar level of SD was identified in two reciprocal $F_{2}$ cross populations, with both nuclear genetic and cytoplasmic factors causing severe SD. This concurs with several prior studies that reported that both nuclear factors (Goloenko et al. 2002; He et al. 2001; Liu and Qu 2008; Wang et al. 2009) and cytoplasmic factors (Faris et al. 1998; Goloenko et al. 2002; Manabe et al. 1999; Wang et al. 2009) play a key role in $\mathrm{SD}$.

In our two $F_{2}$ populations, nuclear genetic factors from Dasanbyeo (indica) had stronger effects on SD than those from Ilpumbyeo (japonica) since most of the distorted loci were skewed in favor of the indica alleles (Table 2, Additional file 2: Table S2 and Additional file 3: Figure S1). These results are consistent with previous observations that SD in segregated populations generated from indicaljaponica hybrids favored the indica parent (Harushima et al. 2002; Wang et al. 2009; Xu et al. 1997). This suggests that indica alleles may be expected to predominate in every inter-subspecific indicaljaponica cross in rice even though the chromosomal regions containing the clusters of distorted markers are not the same. Differences in clusters of distorted markers among populations and/or crossing directions (Harushima et al. 2002; $\mathrm{Xu}$ et al. 1997) should be the results of different mechanism of SD.

$\mathrm{SD}$ in $\mathrm{F}_{2}$ populations possessing indica cytoplasm strongly favored Dasanbyeo (indica) alleles, as did $\mathrm{F}_{2}$ populations possessing japonica cytoplasm (Additional file 2: Table S2). This was somewhat consistent with previous reports that distortion in segregated populations possessing indica cytoplasm favors indica alleles, while populations possessing japonica cytoplasm did not harbor distortion, favoring a specific parental allele ( $\mathrm{He}$ et al. 2001; Peng et al. 2006; Wang et al. 2009).

Among chromosomal regions showing SD, chromosomes 3, 5, 6 and 12 exhibited the most severely distorted markers in one and/or both $\mathrm{F}_{2}$ populations. Moreover, the marker distortion in these chromosomal regions extended across a large portion of the chromosome, and to the whole arm of the chromosome in some cases (Additional file 3: Figure S1). In $F_{2}$ populations, the type of selection (gametic and/or zygotic) responsible for SD can be determined by using maximum-likelihood models proposed by previous studies (Lorieux et al. 1995; Pham et al. 1990; Wang et al. 2005). The assumptions of the proposed models are theoretically simplified for only one or two SD loci and male gametophytic genes involving SD. However, the mechanisms producing the reproductive barriers observed in inter- and intra-specific crosses in rice are complex and variable within different populations (Wu et al. 2010). Thus, in the current study, the type of selection affecting SD was investigated by genotyping a common set of markers in a set of all possible reciprocal $\mathrm{BC}_{1} \mathrm{~F}_{1}$ populations, which contains female-segregating and malesegregating populations. Biologically, SD could result from selection among gametes and/or zygotes, when an allele at a locus diminishes gametic or zygotic fitness, linked loci will deviate from the expected Mendelian segregation ratio (Alheit et al. 2011). Therefore in our study, the number of markers used in reciprocal $\mathrm{BC}_{1} \mathrm{~F}_{1}$ populations should be increased in order to obtain an improved estimate of biological $\mathrm{SD} . \mathrm{BC}_{1} \mathrm{~F}_{1}$ genotyping is an effective approach for the investigation of $\mathrm{SD}$ since this hybridization strategy was able to identify female- and male-function effects and zygotic-selection effects, as well as the effects of cytoplasm and/or cyto-nuclear interaction, on SD.

Our data showed that the level of $\mathrm{SD}$ in $\mathrm{BC}_{1} \mathrm{~F}_{1}$ populations was generally low relative to that in $\mathrm{F}_{2}$ populations, indicating that the cause of SD was simplified into male or female function in each $\mathrm{BC}_{1} \mathrm{~F}_{1}$ population. Nevertheless, Dasanbyeo alleles were transmitted in higher frequencies than Ilpumbyeo alleles in both $\mathrm{F}_{2}$ and $\mathrm{BC}_{1} \mathrm{~F}_{1}$ populations; this concurs with previous studies suggesting that indica alleles are strongly favored in interspecific crosses of rice (Harushima et al. 2002; Wang et al. 2009; Xu et al. 1997). The level of SD among our $\mathrm{BC}_{1} \mathrm{~F}_{1}$ populations also varied greatly. SD frequency was higher in male-segregating populations than in femalesegregating populations, suggesting that the SD observed in our study is strongly driven by male function or pollen competition rather than female function (Table 2).

The SD loci in $\mathrm{F}_{2}$ populations did not always concur with $\mathrm{SD}$ loci in $\mathrm{BC}_{1} \mathrm{~F}_{1}$ populations; for example, although significant $\mathrm{SD}$ was detected at $\mathrm{S} 05064$ in $\mathrm{BC}_{1} \mathrm{~F}_{1}$ populations, no SD at $\mathrm{S} 05064$ was detected in either of the $F_{2}$ populations. The Dasanbyeo allele at S05064 was favored in D/DI and I/DI, but the Ilpumbyeo allele was favored in I/ID. This conflicting preference for parental alleles depending on the male or female gametes might nullify the potential SD in $F_{2}$ populations. Similarly, several SD loci in $\mathrm{BC}_{1} \mathrm{~F}_{1}$ populations were normally segregated in $\mathrm{F}_{2}$ populations. Conversely, all the SD loci found in $\mathrm{F}_{2}$ populations exhibited $\mathrm{SD}$ in $\mathrm{BC}_{1} \mathrm{~F}_{1}$ populations, 
suggesting that the cause of SD loci in $\mathrm{F}_{2}$ populations can be explained by female and/or male function and/or zygotic selection.

It is reported that the linkage distance between markers varies at some chromosomal regions in different crosses and types of population, but the order of markers remains highly conserved (Antonio et al. 1996). In our study, in general, a reduction in the length of the genetic map was observed in male-segregating populations relative to female-segregating populations (Table 1). This suggests that there may have been more recombination in female gametes and thus, recombination frequency between marker pairs in male-segregating populations was lower than those in female-segregating populations. However, the population sizes in this study may not be large enough to draw a conclusion regarding the comparison of recombination frequencies between markers.

\section{Relationships of SD regions to hybrid barriers in rice} In order to determine the relationship between SD loci and hybrid barriers in rice, comparative analysis was conducted based on physical mapping of each SD locus to the Nipponbare Pseudomolecule assembly annotated by IRGSP Build5 (http://www.rgp.dna.affrc.go.jp/). The chromosomal regions of substantial SD loci found in this study were compared to the regions with quantitative trait loci (QTLs) underlying hybrid sterility/fertility and gametophyte genes reported in previous studies on rice. Chromosomal regions with SD loci in this study were mostly related to, or corresponded with, chromosomal regions showing hybrid barriers (gametophyte or sterility gene) regions (Table 4).

Our comparisons revealed interesting regions corresponding to severely distorted loci on chromosomes 3,5 , and 6. The SD chromosomal region spanning 4.74-14.53 Mbp on chromosome 6 that was influenced by female function overlapped with hybrid barriers (Table 4). Hybrid barrier loci overlapping this region were as follows: $\mathrm{cim}$ and $\mathrm{Cif}$, which are responsible for the cross incompatibility reaction in the male and the female, respectively (Matsubara and Khin-Thidar 2003); S1, which is responsible for gamete elimination in O. rufipogon (Koide et al. 2008b); gametophyte genes ga-1 and ga-5 (Kinoshita 1995); S5, a locus with a key effect on embryo sac fertility (Chen et al, 2008; Yang et al. 2012); esa1, which affects embryo sac abortion (Liu et al. 2001); S6, which affects sex-independent SD affecting male and female gametogenesis (Koide et al. 2008a), L6, a locus affecting pollen fertility (He and $\mathrm{Xu} 2000$ ); qSF6.2, which affects spikelet fertility (Reflinur et al. 2012); and the $S 8$ locus for embryo sac sterility (Wan et al. 1993). These loci suggest that the chromosomal region affecting reproductive barriers, especially those influenced by female factors, is mostly conserved on chromosome 6 .

The most severe SD region affected by male function was detected along chromosome 3 (4.3-24.3 Mbp). This chromosomal region overlapped the following loci: the gametophytic genes $g a-2$ and $g a-3$ (Xu et al. 1997); $q H P S$ 3 ,which is responsible for pollen sterility (Chen et al.

\begin{tabular}{|c|c|c|c|c|c|}
\hline$\overline{C h r}$ & Selection type $^{a}$ & Marker (range) & Position (Mbp) & Cross $^{b}$ & Previous studies shared common regions \\
\hline 1 & zygotic & S01011 S01038 & $4.38 \sim 7.46$ & $\mathrm{D} / / \mathrm{D}, \mathrm{DI} / / \mathrm{D}$ & ga-9(Xu et al. 1997); f1 (Wang et al. 1998); qSF1 (Reflinur et al. 2012) \\
\hline 1 & $\mathrm{mSD}$ & S01157B S01181B & $39.8 \sim 43.2$ & $|/ /| \mathrm{D}$ & GB (Harushima et al. 2001) \\
\hline 2 & $\mathrm{mSD}$ & S02126 S02135 & $29.91 \sim 31.48$ & $\mathrm{D} / / \mathrm{DI}$ & \\
\hline \multicolumn{6}{|l|}{2} \\
\hline 3 & $\mathrm{mSD}$ & S03027 S03065 & $5.71 \sim 14.43$ & D//ID, D//D\|I & $\begin{array}{l}\text { ga-2and ga-3(Xu et al. 1997); qHPS-3(Chen et al. 2006); } \\
\text { f3(Wang et al. 1998); S33(Jing et al. 2007); L3b and } \\
\text { S3b(He and Xu 2000; He et al. 1999); sf3.1(Marri et al. 2005); qSF3.1 } \\
\text { and qSF3.2 (Reflinur et al. 2012); }\end{array}$ \\
\hline 5 & $\mathrm{mSD}$ & S05004B S05030B & $0.29 \sim 3.66$ & $\mathrm{D} / / \mathrm{ID}, \mathrm{D} / / \mathrm{DI}$ & $\begin{array}{l}\text { f5(Wang et al. } 2006 \text { ); S24(kubo et al. 2000); S31(Zhao et al. 2007); } \\
\text { 9SF5.2 (Reflinur et al. 2012); }\end{array}$ \\
\hline 5 & $\mathrm{mSD}$ & S05032 S05077A & $4.29 \sim 20.10$ & $\mathrm{D} / / \mathrm{DI}, \mathrm{l} / / \mathrm{ID}$ & GB (Harushima et al. 2002); aHPS-5(Chen et al. 2006); \\
\hline 6 & fSD & S06018 S06065A & $4.74 \sim 14.53$ & $\mathrm{ID} / / \mathrm{l}, \mathrm{DI} / / \mathrm{D}, \mathrm{DI} / / \mathrm{I}$ & $\begin{array}{l}\text { ga-1, ga-4 and ga-5(Kinoshita 1995) ; S5(Chen et al. 2008); } \\
\text { S6(Koide et al. 2008a); esa-1(Liu et al. 2001); L6(He and Xu 2000); } \\
\text { S8(Wan et al. 1993); 9SF6.2 (Reflinur et al. 2012); }\end{array}$ \\
\hline 8 & $\mathrm{mSD}$ & S08060-S08090 & $17.27 \sim 23.08$ & $\mid / / \mathrm{ID}$ & S27(Sobrizal and Yoshimura 2001) \\
\hline 12 & $\mathrm{mSD}$ & S12009A S12011B & $0.63 \sim 1.88$ & $\mathrm{D} / / \mathrm{ID}, \mathrm{D} / / \mathrm{DI}, \mathrm{I} / \mathrm{DI}$ & qSF12.2 (Reflinur et al. 2012); Iwr12.1(Li et al. 2004) \\
\hline 12 & fSD & S12066 S12097B & $19.44 \sim 25.00$ & $\mathrm{DI} / / \mathrm{D}$ & \\
\hline
\end{tabular}

\footnotetext{
${ }^{a}$ Abbreviations are the same as in Table 3.
}

${ }^{\mathrm{b}}$ Abbreviations are the same as in Table 2. 
2006); $f 3$ (Wang et al. 1998); sf3.1 (Marri et al. 2005); S33 (Jing et al. 2007); qSF3.1 and qSF3.2, loci responsible for spikelet sterility (Reflinur et al. 2012); and the $L 3 b$ and $S 3 b$ loci, which affect both pollen and spikelet fertility (He and $\mathrm{Xu}$ 2000; He et al. 1999). Relevant with several findings of sterility loci located in this region, it is likely that male function contributes to hybrid barriers which may lead SD on chromosome 3.

The distorted chromosomal region on chromosome 5 (0.29-20.66Mbp) was affected by male function and overlapped with the following loci: $f 5$ (Wang et al. 2006) and S24 (Kubo et al. 2000), which affect pollen sterility; S31, a locus affecting embryo sac sterility in rice (Zhao et al. 2007); qSF5.2, a locus responsible for spikelet fertility (Reflinur et al. 2012); qHSPS-5, which affects hybrid pollen sterility (Chen et al. 2006); and a gametophyte barrier (Harushima et al. 2002).

SD-containing chromosomal regions that did not correspond to or overlap hybrid barriers (either gametophyte or sterility genes) regions were detected on chromosome 2 (region for $\mathrm{mSD}$ at $29.91-31.48 \mathrm{Mbp}$ of Nipponbare Pseudomolecule) and chromosome 12 (region for fSD at region of 19.44-25.00 Mbp). These findings suggest that the key factors on these chromosomal regions might be new gametophyte regions that influence SD.

One zygotic-selection-affected SD regions on chromosomes 1 overlapped with hybrid barrier regions that were identified in previous studies (Table 4). SD loci on chromosome 1 corresponded to gametophyte barrier, ga-9 (Xu et al. 1997), f1 (Wang et al. 1998), and qSF1 (Reflinur et al. 2012).

Our finding that zygotic selection affects SD on chromosomes 1 conflicts with previous research from Harushima et al. (2002), which found that SD on these chromosomal regions was caused by gametophyte barrier. This may be due to the different genetic backgrounds of the backcross populations used in the previous study and in our study. In addition, no reciprocal backcrosses were performed in the previous study to confirm the action of zygotic selection on SD.

\section{Conclusions}

Taken together, based on the $\mathrm{SD}$ analysis in reciprocal $\mathrm{F}_{2}$ populations, we summarized that both nuclear genetic and cytoplasm factors from Dasanbyeo (indica) had stronger effects on SD than those from Ilpumbyeo (japonica). The gametophytic (female and male gamete function) and zygotic selection as mechanisms underlying SD could be explained by the distorted marker patterns using early generation of reciprocal backcross populations. The identification of SD distribution and the effect of genetic factors causing SD that were identified in the present study will provide not only a basis for future research on the elucidation of the molecular mechanisms underlying SD in rice, but also information beneficial for breeding strategies.

\section{Methods}

Plant materials

Ten reciprocal crosses consisting of two $F_{2}$ and eight $\mathrm{BC}_{1} \mathrm{~F}_{1}$ populations developed from Korean elite japonica variety, Ilpumbyeo, and Korean indica variety, Dasanbyeo, were used for genetic studies on SD analysis in intersubspecific crosses of rice. A total of $210 \mathrm{~F}_{2}$ progeny (ID) derived from the cross of Ilpumbyeo (female parent) and Dasanbyeo (male parent) and $199 \mathrm{~F}_{2}$ progeny (DI) of the reciprocal cross were used. Eight reciprocal $\mathrm{BC}_{1} \mathrm{~F}_{1}$ populations were subsequently developed to distinguish female meiotic drive from male-specific sources of distortion, and gametic mechanisms from differential selection against zygote, as described in detail in Figure 2. The numbers of

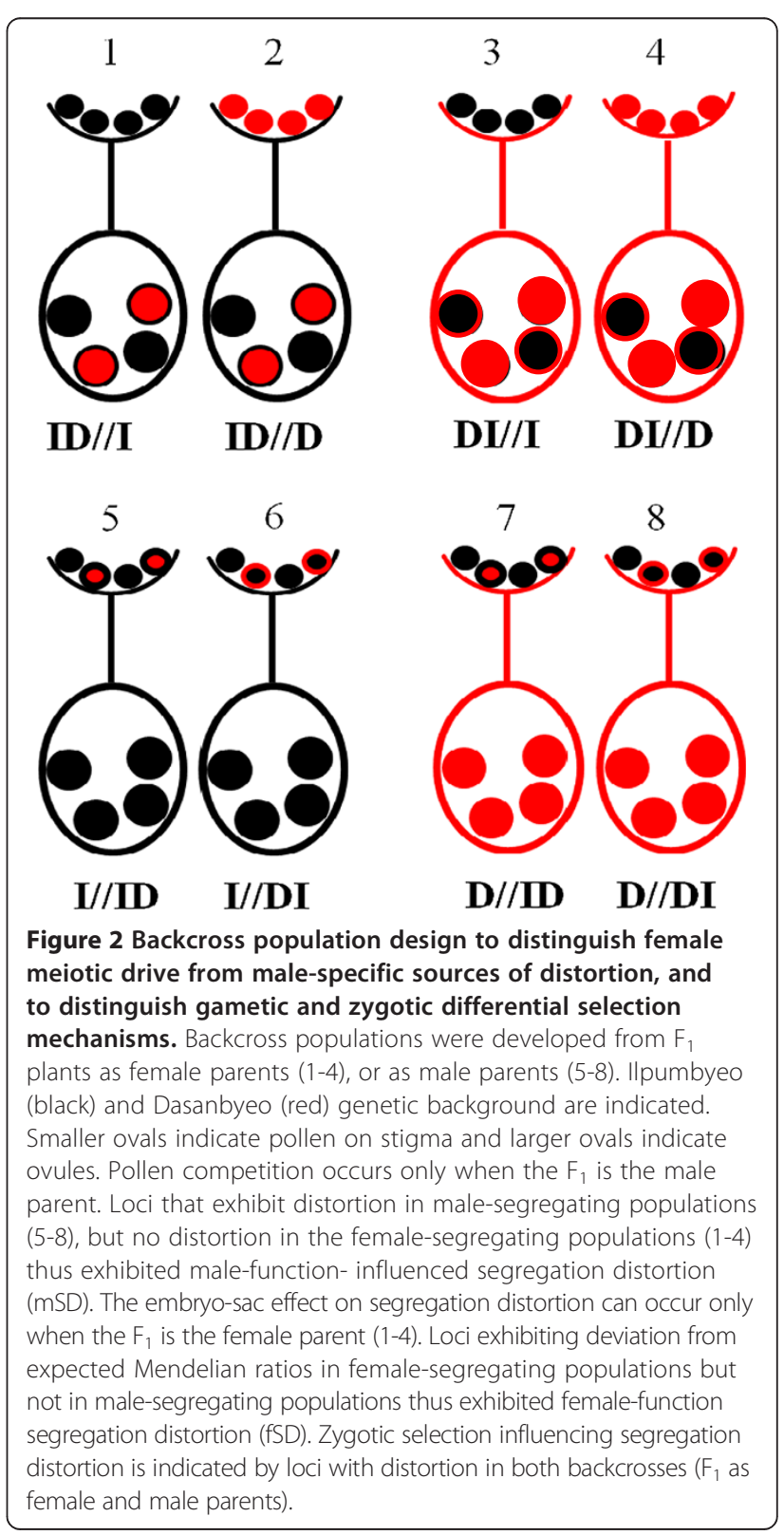


progeny from the $\mathrm{BC}_{1} \mathrm{~F}_{1}$ crosses used for mapping and for SD analysis were as follows: 88 from ID//I, 25 from I//ID, 69 from DI//D, 69 from D//DI, 71 from ID//D, 52 from D//ID, 68 from DI//I, and 27 from I//DI population. All plant materials were planted during rice-growing season 2009, at the experimental farm of Seoul National University, Suwon, Korea. Thirty-day-old seedlings were transplanted to irrigated field condition at one seedling per hill with a $30 \times 15 \mathrm{~cm}$ of spacing between seedlings. Field management was carried out following normal agronomic practices. Fertilizers were properly applied at the rate of $100 \mathrm{~kg} \mathrm{~N} \mathrm{ha}^{-1}, 80 \mathrm{~kg} \mathrm{P} \mathrm{ha}{ }^{-1}$, and $80 \mathrm{~kg} \mathrm{~K} \mathrm{ha}^{-1}$ (100-80-80 kg/ha N-P-K).

\section{Molecular marker analysis}

DNA was extracted from young leaf blades according to the method of Causse et al. (1994), DNA samples from the $\mathrm{F}_{2}$ and $\mathrm{BC}_{1} \mathrm{~F}_{1}$ populations were genotyped using 107 and 144 STS primers, respectively. These STS markers are dispersed throughout the rice genome and the primers used were designed by the Crop Molecular Breeding Lab, Seoul National University (Chin et al. 2007). Polymerase chain reaction (PCR) analysis and visualization of amplicons in the $\mathrm{F}_{2}$ and $\mathrm{BC}_{1} \mathrm{~F}_{1}$ populations was performed as described previously (Reflinur et al. 2012).

\section{Data analysis}

Linkage map construction in $\mathrm{F}_{2}$ and $\mathrm{BC}_{1} \mathrm{~F}_{1}$ populations was performed with Mapmaker/EXP 3.0 program. A LOD threshold of 3.0 was used for declaring linkage (Lander et al. 1987; Lincoln et al. 1992), and the Kosambi function was used to convert recombinant value to the genetic distances between the markers (Kosambi 1944). For the segregation data of each marker, deviations from the Mendelian ratios (1:2:1 ratio for $F_{2}$ populations or 1:1 ratio for $\mathrm{BC}_{1} \mathrm{~F}_{1}$ populations) were tested using chi-square analysis. A non-parametric technique using sequential Bonferroni method (Rice 1989) was applied to the segregation data of each population in order to avoid type-I error deriving from the large number of tests.

\section{Additional files}

Additional file 1: Table S1. Physical locations of both end markers for each chromosome and linkage map coverage of the genome in two reciprocal $F_{2}$ and eight $B C_{1} F_{1}$ populations.

Additional file 2: Table S2. Chi-square test for SD of markers and genetic factors influencing distorted markers in two reciprocal $F_{2}$ generated from Ilpumbyeo and Dasanbyeo parents.

Additional file 3: Figure S1. Genotype frequencies of STS markers along chromosomes $3,5,6$, and 12 in two reciprocal $F_{2}$ populations generated from Ilpumbyeo and Dasanbyeo parents.

Additional file 4: Figure S2. Chromosomal location of pronounced SD loci observed in genetic linkage maps in the two reciprocal $F_{2}$ and eight $\mathrm{BC}_{1} \mathrm{~F}_{1}$ populations.
Competing interests

The authors declare that they have no competing interests.

\section{Authors' contributions}

$R$ produced plant materials, performed data analysis, and wrote the manuscript. SHC and BK contributed to field experiments. SMJ, MBA, YB, JHC and $J$ contributed to DNA extractions and collection of molecular data, and critically reviewed the manuscript. HJK conceived and designed the study and wrote the manuscript. All the authors read and approved the final manuscript.

\section{Acknowledgements}

This work was supported by a grant from the Next-Generation BioGreen 21 Program (Plant Molecular Breeding Center, No. PJ008125) of the Rural Development Administration, Korea.

\section{Author details}

'Department of Plant Science, Plant Genomics and Breeding Institute, and Research Institute for Agriculture and Life Sciences, Seoul National University, Seoul 151-921, Korea. ${ }^{2}$ Indonesian Center for Agricultural Biotechnology and Genetic Resources Research and Development, IAARD, Bogor, Indonesia. 3.Department of Applied Bioscience, Konkuk University, Seoul 143-701, Korea. ${ }^{4}$ International Rice Research Institute, Los Banos, Philippines.

Received: 13 October 2013 Accepted: 31 March 2014

Published online: 07 August 2014

\section{References}

Alheit KV, Reif JC, Maurer HP, Hahn V, Weissmann EA, Miedaner T, Würschum T (2011) Detection of segregation distortion loci in triticale ( $X$ TriticosecaleWittmack) based on a high-density DArT marker consensus genetic linkage map. BMC Genomics 12:380

Antonio BA, Inoue T, Kajiya H, Nagamura Y, Kurata N, Minobe Y, Yano M, Nakagahra M, Sasaki T (1996) Comparison of genetic distance and order of DNA markers in five populations of rice. Genome 39:946-956

Causse MA, Fulton TM, Cho YG, Ahn SN, Chunwongse J, Wu KS, Xiao JH, Yu ZH, Ronald PC, Harrington SE, Second G, McCouch SR, Tanksley SD (1994) Saturated molecular map of the rice genome based on an interspecific backcross population. Genetics 138:1251-1274

Chen J, Jiang L, Wang CM, Ikehashi H, Zhai HQ, Wan JM (2006) Mapping of loci for pollen sterility of indica/japonica hybrids in rice (Oryza sativa L.). Acta Agr Sinica 32:515-521

Chen JJ, Ding JH, Ouyang YD, Du HY, Yang JY, Cheng K, Zhao J, Qiu SQ, Zhang $X L$, Yao JL, Liu KD, Wang L, Xu CG, Li XH, Xue YB, Xia M, Ji Q, Lu JF, Xu ML, Zhang QF (2008) A triallelic system of S5 is a major regulator of the reproductive barrier and compatibility of indica-japonica hybrids in rice. Proc Natl Acad Sci 105:11436-11441

Chin JH, Kim JH, Jiang W, Chu SH, Woo MO, Han L, Brar D, Koh HJ (2007) Identification of subspecies-specific STS markers and their association with segregation distortion in rice (Oryza sativa L.). J Crop Sci Biotechnol 10:175-184

Faris JD, Laddomada B, Gill BS (1998) Molecular mapping of segregation distortion loci in Aegilopstauschii. Genetics 149:319-327

Fishman L, Willis JH (2005) A novel meiotic drive locus almost completely distorts segregation in Mimulus (monkeyflower) hybrids. Genetics 169:347-353

Fishman L, Kelly AJ, Morgan E, Willis JH (2001) A genetic map in the Mimulus guttatus species complex reveals transmission ratio distortion due to heterospecific interactions. Genetics 159:1701-1716

Fishman L, Aagaard J, Tuthill JC (2008) Toward the evolutionary genomics of gametophytic divergence: Patterns of transmission ratio distortion in monkeyflower (Mimulus) hybrids reveal a complex genetic basis for conspecific pollen precedence. Evolution 62:2958-2970

Goloenko IM, Davydenko OG, Shimkevich AM (2002) Segregation distortion of marker nuclear genes in alloplasmic and isoplasmic lines of barley. Russian J Genet 38:791-795

Harushima Y, Kurata N, Yano M, Nagamura Y, Sasaki T, Minobe Y, Nakagahra M (1996) Detection of segregation distortions in an indica-japonica rice cross using a high-resolution molecular map. Theor Appl Genet 92:145-150

Harushima Y, Yano M, Shomura P, Sato M, Shimano T, Kuboki Y, Yamamoto T, Lin SY, Antonio BA, Parco A, Kajiya H, Huang N, Yamamoto K, Nagamura Y, 
Kurata N, Khush GS, Sasaki T (1998) A high-density rice genetic linkage map with 2275 markers using a single $F_{2}$ population. Genetics 148:479-494

Harushima Y, Nakagahra M, Yano M, Sasaki T, Kurata N (2001) A genome-wide survey of reproductive barriers in an intraspecific hybrid. Genetics 159:883-892

Harushima Y, Nakagahra M, Yano M, Sasaki T, Kurata N (2002) Diverse variation of reproductive barriers in three intraspecific rice crosses. Genetics 160:313-322

He YQ, Xu CG (2000) Importance of epistasis as the genetic basis of sterility instability for photoperiod-sensitive genic male sterile rice. Acta B Sinica 42:1062-1068

He YQ, Yang J, Xu CG, Zhang ZG, Zhang Q (1999) Genetic bases of instability of male sterility and fertility reversibility in photoperiod-sensitive genic malesterile rice. Theor Appl Genet 99:683-693

He P, Li JZ, Zheng XW, Shen LS, Lu CF, Chen Y, Zhu LH (2001) Comparison of molecular linkage maps and agronomic trait loci between $\mathrm{DH}$ and RIL populations derived from the same rice cross. Crop Sci 41:1240-1246

Jing W, Zhang WW, Jiang L, Chen LM, Zhai HQ, Wan JM (2007) Two novel loci for pollen sterility in hybrids between the weedy strain Ludao and the Japonica variety Akihikari of rice (Oryza sativa L.). Theor Appl Genet 114:915-925

Kinoshita T (1995) Report of the committee on gene symbolization, nomenclature and linkage groups. Rice Genet Newsl 12:9-93

Koide Y, Ikenaga M, Sawamura N, Nishimoto D, Matsubara K, Onishi K, Kanazawa A, Sano Y (2008a) The evolution of sex-independent transmission ratio distortion involving multiple allelic interactions at a single locus in rice. Genetics 180:409-420

Koide Y, Onishi K, Nishimoto D, Baruah AR, Kanazawa A, Sano Y (2008b) Sex-independent transmission ratio distortion system responsible for reproductive barriers between Asian and African rice species. New Phytol 179:888-900

Koide Y, Shinya Y, Ikenaga M, Sawamura N, Matsubara K, Onishi K, Kanazawa A, Sano $Y$ (2011) Complex genetic nature of sex-independent transmission ratio distortion in Asian rice species: the involvement of unlinked modifiers and sex-specific mechanisms. Heredity 108:242-247

Kosambi DD (1944) The estimation of map distances from recombination values. Ann Eugenics 12:172-175

Kubo T, Eguchi M, Yoshimura A (2000) A new gene for F1 pollen sterility in Japonica/Indica cross of rice. Rice Genet Newsl 17:63-69

Lander ES, Green P, Abrahamson J, Barlow A, Daly MJ, Lincoln SE, Newberg LA (1987) MAPMAKER: an interactive computer package for constructing primary genetic linkage maps of experimental and natural populations. Genomics 1:174-181

Li JM, Xiao JH, Grandillo S, Jiang LY, Wan YZ, Deng QY, Yuan LP, McCouch SR (2004) QTL detection for rice grain quality traits using an interspecific backcross population derived from cultivated Asian (O. sativa L.) and African (O. glaberrima S.) rice. Genome 47:697-704

Lin SY, Ikehashi H, Yanagihara S, Kawashima A (1992) Segregation distortion via male gametes in hybrids between Indica and Japonica or wide-compatibility varieties of rice (Oryza sativa L). Theor Appl Genet 84:812-818

Lincoln S, Daly M, Lander ES (1992) Constructing genetic maps with MAPMAKER/ EXP 3.0. Whitehead Institute Technical Report, 2nd edn. Whitehead Institute, Cambridge, Massachusetts, USA

Liu JJ, Qu LJ (2008) Meiotic and mitotic cell cycle mutants involved in gametophyte development in Arabidopsis. Mol Plant 1:564-574

Liu YS, Zhu LH, Sun JS, Chen Y (2001) Mapping QTLs for defective female gametophyte development in an inter-subspecific cross in Oryza sativa L. Theor Appl Genet 102:1243-1251

Liu GJ, Bernhardt JL, Jia MH, Wamishe YA, Jia YL (2008) Molecular characterization of the recombinant inbred line population derived from a japonica/indica rice cross. Euphytica 159:73-82

Lorieux M, Perrier X, Goffinet B, Lanaud C, Deleon DG (1995) Maximum-likelihood models for mapping genetic-markers showing segregation distortion. 2. $F_{2}$ populations. Theor Appl Genet 90:81-89

Lyttle TW (1991) Segregation distorters. Ann Rev Genet 25:511-557

Manabe M, Ino T, Kasaya M, Takumi S, Mori N, Ohtsuka I, Nakamura C (1999) Segregation distortion through female gametophytes in interspecific hybrids of tetraploid wheat as revealed by RAPD analysis. Hereditas 131:47-53

Marri PR, Sarla N, Reddy LV, Siddiq EA (2005) Identification and mapping of yield and yield related QTLs from an Indian accession of Oryza rufipogon. BMC Genet 6:33
Matsubara K, Khin-Thidar SY (2003) A gene block causing cross-incompatibility hidden in wild and cultivated rice. Genetics 165:343-352

Matsushita S, Iseki T, Fukuta Y, Araki E, Kobayashi S, Osaki M, Yamagishi M (2003) Characterization of segregation distortion on chromosome 3 induced in wide hybridization between indica and japonica type rice varieties. Euphytica 134:27-32

Peng Y, Liang YS, Wang SQ, Wu FQ, Li SC, Deng QM, Li P (2006) Analysis of segregation distortion of SSR markers in the RI population of rice. Mol Plant Breed 4:786-790

Pham JL, Glaszmann JC, Sano R, Barbier P, Ghesquiere A, Second G (1990) Isozyme markers in rice: genetic analysis and linkage relationships. Genome 33:348-359

Reflinur CJH, Jang SM, Kim B, Lee J, Koh HJ (2012) QTLs for hybrid fertility and their association with female and male sterility in rice. Gene Genomics 34:355-365

Rice WR (1989) Analyzing tables of statistical tests. Evolution 43:223-225

Sandler L, Novitski E (1957) Meiotic drive as an evolutionary force. Am Nat 91:105-110

Sobrizal MY, Yoshimura A (2001) Mapping of a gene for pollen semi-sterility on rice chromosome 8 of rice. Rice Genet Newsl 18:59-61

Taylor DR, Ingvarsson PK (2003) Common features of segregation distortion in plants and animals. Genetica 117:27-35

Wan JM, Yanagihara S, Kato H, Ikehashi H (1993) Multiple alleles at a new locus causing hybrid sterility between a Korean indica variety and a javanica variety in rice (Oryza sativa L). Jap J Breed 43:507-516

Wang J, Liu KD, Xu CG, Li XH, Zhang QF (1998) The high level of wide compatibility of variety 'Dular' has a complex genetic basis. Theor Appl Genet 97:407-412

Wang CM, Zhu CS, Zhai HQ, Wan JM (2005) Mapping segregation distortion loci and quantitative trait loci for spikelet sterility in rice (Oryza sativa L.). Genet Res 86:97-106

Wang GW, He YQ, Xu CG, Zhang QF (2006) Fine mapping of f5-Du, a gene conferring wide-compatibility for pollen fertility in inter-subspecific hybrids of rice (Oryza sativa L.). Theor Appl Genet 112:382-387

Wang SH, Tan XL, Tan YL, Zhang ZL, Wen JC, Kou SY (2009) Segregation distortion detected in six rice $F_{2}$ populations generated from reciprocal hybrids at three altitudes. Genet Res 91:345-353

Wu YP, Ko PY, Lee WC, Wei FJ, Kuo SC, Ho SW, Hour AL, Hsing Yl, Lin YR (2010) Comparative analyses of linkage maps and segregation distortion of two $F_{2}$ populations derived from japonica crossed with indica rice. Hereditas 147:225-236

Xu Y, Zhu L, Xiao J, Huang N, McCouch SR (1997) Chromosomal regions associated with segregation distortion of molecular markers in $F_{2}$, backcross, doubled haploid, and recombinant inbred populations in rice (Oryza sativa L). Mol Gen Genet 253:535-545

Yang J, Zhao X, Cheng K, Du H, Ouyang Y, Chen J, Qiu S, Huang J, Jiang Y, Jiang L, Ding J, Wang J, Xu C, Li X, Zhang Q (2012) A killer-protector system regulates both hybrid sterility and segregation distortion in rice. Science 337:1336-1340

Yano M, Harushima Y, Shomura P, Sato M, Shimano T, Kuboki Y, Yamamoto T, Lin SY, Antonio BA, Parco A, Kajiya H, Huang N, Yamamoto K, Nagamura Y, Kurata N, Khush GS, Sasaki T (1998) A high-density rice genetic linkage map with 2275 markers using a single $F_{2}$ population. Genetics 148:479-494

Zhao ZG, Jiang L, Zhang WW, Yu CY, Zhu SS, Xie K, Tian H, Liu LL, Ikehashi H, Wan JM (2007) Fine mapping of S31, a gene responsible for hybrid embryo-sac abortion in rice (Oryza sativa L.). Planta 226:1087-1096

doi:10.1186/s12284-014-0003-8

Cite this article as: Reflinur et al:: Analysis of segregation distortion and its relationship to hybrid barriers in rice. Rice 2014 7:3. 